\title{
Diamonds from the Renard kimberlites, Quebec
}

\author{
Lucy Hunt $^{1}$, Thomas Stachel ${ }^{1}$ and Tom E. McCandless ${ }^{1,2}$ \\ ${ }^{1}$ Department of Earth and Atmospheric Sciences, University of Alberta, Edmonton, AB, Canada, T6G 2E3 \\ ${ }^{2}$ Stornoway Diamond Corporation, Unit 118-980, West First Street, North Vancouver, BC, Canada, V7P $3 N 4$
}

\section{Introduction}

The Superior Province in Eastern Canada is one of the largest Archean cratons in the world. Along with other Archean cratons and Proterozoic orogens it makes up the Canadian Shield (Hoffman, 1988). Within the Superior craton deep-seated mantle-derived igneous rocks, including kimberlite, "melnoite" and ultramafic lamprophyre form widespread diatremes ("pipes") and dikes (Birkett et al., 2004 and references therein). The eruption centers are distributed in seven distinct fields, with the Renard kimberlite cluster studied here being located within the Otish Mountain Field.

At Renard nine kimberlite bodies have been identified, located within a $2 \mathrm{~km}^{2}$ area in the northern Otish Mountains of Quebec (Fig. 1). The bodies were emplaced into the Archean trondjhemite tonalite gneiss terrane of the eastern Superior province. Previous work on the mineralogy of the kimberlites has shown them to be in the overlap region between kimberlite and rocks of a "melnoitic" character (Birkett et al., 2004).

Radiometric dating of the hypabyssal (coherent) portions of the Renard kimberlites indicate emplacement ages from $\sim 631-645 \mathrm{Ma}$ (Birkett et al., 2004; Fitzgerald et al., 2008). This makes this kimberlite field one of the oldest in Canada, similar in eruption age to the Wemindji kimberlites (629 $\pm 29 \mathrm{Ma}$ : Letendre et al., 2003). Collectively, these emplacement events are broadly coeval with the conversion from subduction magmatism to rifting in northern Laurentia.

\section{Diamond Characteristics}

Morphology: This study focuses on a subset of 56 inclusion-bearing diamonds from early-stage exploration dense media concentrates from Renard 1, 2, 3, 4 and 65. The stones range in mass from 0.01 to 0.76 carats, equating to the $+0.85-3.35 \mathrm{~mm}$ Tyler sieve range, or the +1 to +11 DTC sieve range. Initial morphological analyses showed the diamonds to be predominantly rounded dodecahedra (tetrahexahedroids) (43\%) with only $13 \%$ remaining in the primary unresorbed octahedral form. Twins comprise $25 \%$ of the diamonds, aggregates (intergrowths of more than two crystals) are rare $(5 \%)$. The remainder comprise fragments $(11 \%)$ and pseudohemimorphic stones $(4 \%)$. In this small selection of diamonds no discernable morphological differences were noted between the different pipes.

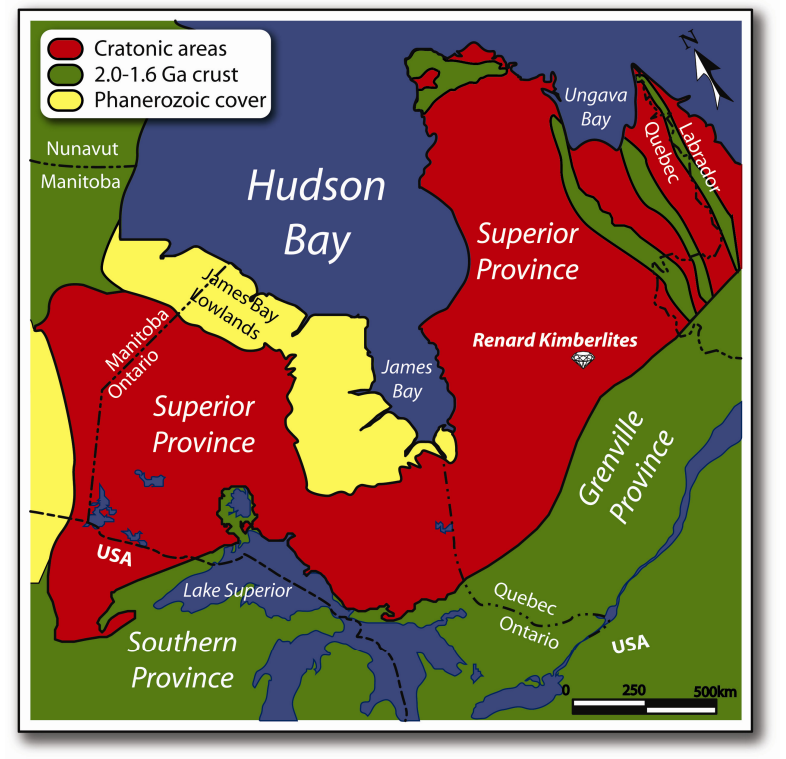

Fig 1. Map showing the location of the Renard kimberlite pipes and the simplified geology of the area, adapted using (Hoffman, 1988).

Colour: A high proportion of the diamonds have a pale colour, typically yellow (39\%) to brown (34\%). Whilst yellow diamond colour is caused by nitrogen impurities (Harris, 1987), brown colouration is attributed to defects in the crystal lattice due to strain (Harris, 1987). The remaining stones are classified as colourless.

Surface Features: Surface features are related to the morphology of the diamonds, with specific features restricted to dodecahedral faces, and others seen only on octahedral faces. As a consequence of the dominance of dodecahedral stones in the sample set features created by the resorption of octahedral growth layers dominate. These features include hillocks and terracing. Trigons are common on all but a few of the residual octahedral faces. Dark green spots were recognised on $18 \%$ of the samples and are particularly abundant in pipes 4 and 65 . These spots originate through alpha particle irradiation and indicate prolonged contact with radioactive minerals (Harris, 1987). Plastic deformation lines visible on resorbed faces are commonly associated with brown colouration.

Rare surface features include tetragons on $\{100\}$ fracture faces and, observed in only one case, microdisk patterns.

These physical characteristics for inclusion-bearing subset differ from larger populations of Renard diamonds. An unbiased selection of 97 unbroken stones 
from Renard 2 in roughly the same size range consists of $7 \%$ octahedra, $45 \%$ dodecahedra, $7 \%$ twins, and $41 \%$ aggregates, the latter being dominated by gray resorbed forms. The greater amount of octahedra and twins relative to aggregates in the inclusion-bearing subset likely reflects the greater ease in identifying inclusions from these shapes relative to aggregates.

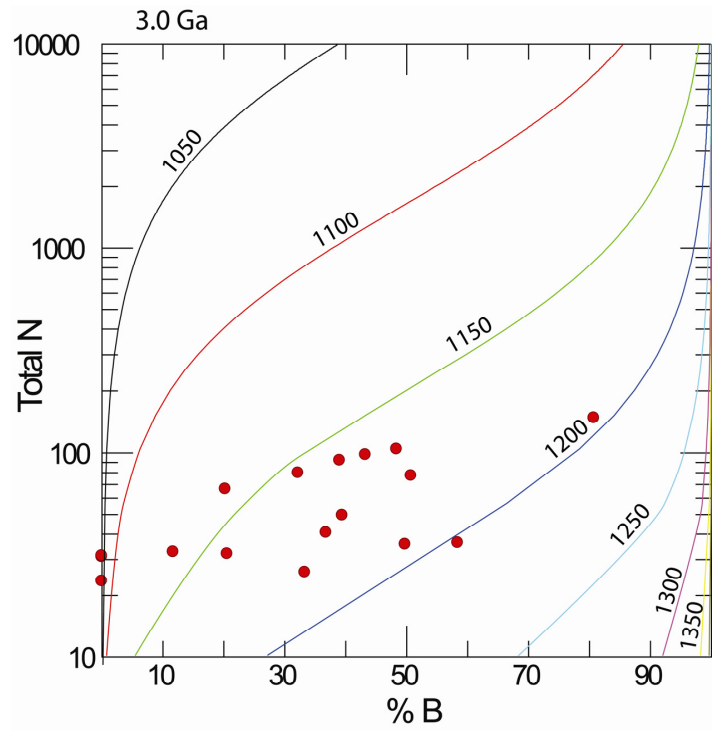

Fig 2. Time averaged mantle residence temperatures for an assumed 3Ga mantle residence time. Calculated from Leahy and Taylor (1997) and Taylor et al. (1990)

\section{Nitrogen Content and Aggregation State}

Nitrogen may substitute for carbon atoms in the diamond lattice. Based on the aggregation state of these nitrogen impurities, diamonds may be classified as Type $\mathrm{Ib}$ (not aggregated), IaA (intermediate aggregation, $>90 \%$ of nitrogen in A-centres) and $\mathrm{IaB}$ (fully aggregated with $>90 \%$ of nitrogen in B-centres.

The Renard diamonds analysed to date have nitrogen contents ranging from $0-148 \mathrm{ppm}$. Variation is seen in both aggregation state and nitrogen content and extends to the level of individual stones. The Renard diamonds are predominantly type IaAB $(52 \%)$ with a further $32 \%$ classified as Type II (nitrogen below detection limit $(\sim 10 \mathrm{ppm}))$. Overall, nitrogen contents and aggregation states are consistent with world wide occurrences.

The variation in nitrogen content and aggregation state seen within individual Renard diamonds reflects changing conditions during diamond growth. This may be a consequence of changing nitrogen content in the diamond growth region or changing temperature conditions. For example, decreasing temperature would cause outward decreasing nitrogen aggregation. Variations in aggregation state seen among diamonds may represent variation in age or time averaged residence temperature.

Time averaged mantle residence temperatures can be determined (calculated from Leahy and Taylor, 1997; Taylor et al., 1990) using nitrogen content and aggregation state, and an assumed mantle residence time. Calculated for a $3 \mathrm{Ga}$ mantle residence time, mantle storage occurred at temperatures ranging from 1100 $1200^{\circ} \mathrm{C}$, with the majority falling between $1150-1200^{\circ} \mathrm{C}$ (Fig. 2). The most likely reason for the observed spread in Figure 2 is sampling of diamonds by the Renard kimberlites at different depths in the lithospheric mantle and therefore at different residence temperatures: Deeper formed diamonds reside at higher temperatures and therefore are more aggregated.

\section{Mineral Inclusions}

Based on microscopic examination, mineral inclusions in Renard diamonds appeared to be peridotitic in paragenesis, with abundant red chromite and colourless phases assumed to be olivine or orthopyroxene. Garnet inclusions are rare but those identified were purple in colour, indicative of a peridotitic assemblage.

Subsequent microprobe analyses of a first batch of recovered inclusions have identified both peridotitic and possible eclogitic phases (Table 1). The colourless inclusions analysed to date have been recognised in individual diamonds as either olivine (typical of peridotitic diamonds) or coesite (a high pressure polymorph typical of $\mathrm{SiO}_{2}$ ). In addition, chromite and one subcalcic garnet have been found, also belonging to the peridotic inclusion suite.

The presence of relatively abundant $\mathrm{SiO}_{2}$ inclusions is unusual. Worldwide, coesite is an uncommon inclusion phase in diamond, forming $\sim 2 \%$ of observed eclogitic inclusions (Stachel, 2007). Rare localities where coesite inclusions are fairly abundant are Guaniamo (Sobolev et al., 1998) and Argyle (e.g. Jaques et al., 1989).

In Guaniamo the presence of abundant coesite has been used to suggest a silica rich protolith, such as a subducted basalt (Schulze et al., 2003; Sobolev et al., 1998). Whilst this remains a viable hypothesis for Renard as well, the lack of other usually more representative eclogitic inclusions such as grossular rich garnet or omphacitic clinopyroxene is unusual. Alternatively, carbonation reactions occurring in a peridotite source also have the ability to create free $\mathrm{SiO}_{2}$ (Wyllie and Huang, 1976). The reactions would occur in localised regions of the lithosphere e.g. along veins. Carbonation reactions could create the limited $\mathrm{SiO}_{2}$ inclusions assemblage and, at the same time, provide a possible source for diamond carbon.

Assuming an initial lherzolitic assemblage of forsterite, orthopyroxene and clinopyroxene, at high enough pressures and with an excess of $\mathrm{CO}_{2}$ the assemblage magnesite and $\mathrm{SiO}_{2}$ can be formed (Fig. 3).

Diamond 12013 contained both a garnet and olivine inclusion. Using the iron magnesium exchange thermometer of O'Neill and Wood (1979) a temperature of $1150^{\circ} \mathrm{C}$ was determined. This is in agreement with the $\mathrm{T}_{\text {Nitrogen }}$ temperatures determined for the same diamond, which gave temperatures of $1200^{\circ} \mathrm{C}$ and $1160^{\circ} \mathrm{C}$ for the two analysed fragments. 


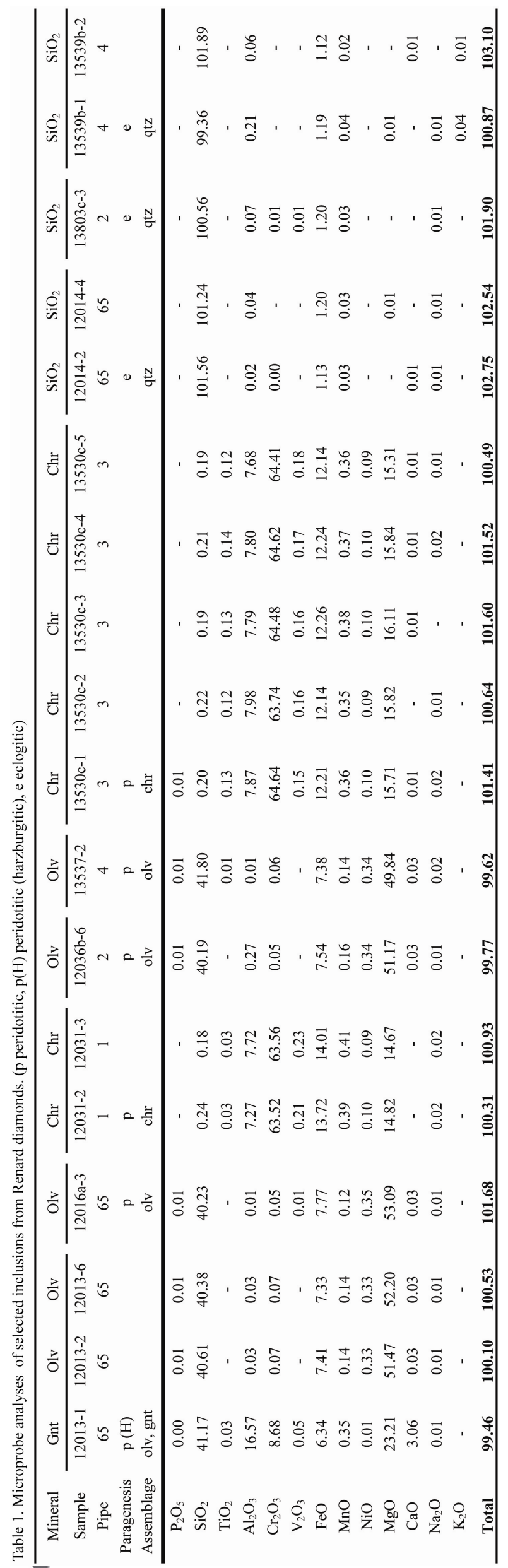

\section{Conclusion}

The nitrogen content and aggregation state of the Renard diamonds is similar to worldwide data. Two distinct inclusion assemblages have been determined. A peridotitic (harzburgitic) assemblage was recognised based on the identification of olivine, Mg-chromite and a G10 garnet. $\mathrm{A} \mathrm{SiO}_{2}$ inclusion assemblage may represent an eclogitic silica rich source. Considering the absence of other eclogitic inclusions phases, this assemblage could represent a peridotitic source with coesite forming during localised carbonation reactions in veins.

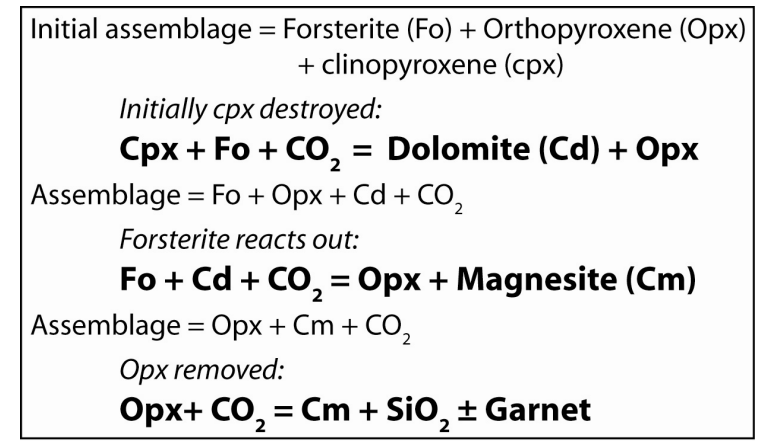

Fig. 3. Equations for the production of $\mathrm{SiO}_{2}$ by carbonation, adapted from Wyllie and Huang (1976).

\section{References:}

Birkett, T.C., McCandless, T.E. and Hood, C.T., 2004. Petrology of the Renard igneous bodies: host rocks for diamond in the northern Otish Mountains region, Quebec. Lithos, 76(1-4): 475-490.

Fitzgerald, C.E., Hetman, C.M., Lepine, I.M., Skelton, D.S. and

McCandless, T.E., 2008. The internal geology and emplacement history of the Renard 2 kimberlite, Superior Province, Canada. Extended Abstract - 9th International Kimberlite Conference, Frankfurt, 2008.

Harris, J.W., 1987. Recent physical, chemical, and isotopic research of diamonds. In: P.H. Nixon (Editor), Mantle Xenoliths. John Wiley and Sons.

Hoffman, P.F., 1988. United Plates of America, the Birth of a Craton Early Proterozoic Assembly and Growth of Laurentia. Annual Review of Earth and Planetary Sciences, 16: 543-603.

Jaques, A.L. et al., 1989. Composition of crystalline inclusions and Cisotopic composition of Argyle and Ellendale diamonds. In: J. Ross et al. (Editors), Kimberlites and Related Rocks. Geological Society of Australia, Special Publication 14, vol. 2. Blackwell, Carlton, pp. 966989.

Leahy, K. and Taylor, W.R., 1997. The influence of the Glennie domain deep structure on the diamonds in Saskatchewan kimberlites. Geologiya I Geofizika, 38(2): 451-460.

Letendre, J.P.L., L'Heureux, M., Nowicki, T.E. and Creaser, R.A., 2003. The Wemindji kimberlites: exploration and geology., Proceedings of the 8th International Kimberlite conference, Victoria, B.C., pp. 71.

O'Neill, H.S.C. and Wood, B.J., 1979. An experimental study of the ironmagnesium partitioning between garnet and olivine and its calibration as a geothermometer. Contributions to Mineralogy and Petrology, 70: 5970

Schulze, D.J., Harte, B., Valley, J.W., Brenan, J.M. and Channer, D.M.D.R., 2003. Extreme crustal oxygen isotope signatures preserved in coesite in diamond. 423(6935): 68-70.

Sobolev, N.V., Yefimova, E.S., Channer, D.M.D., Anderson, P.F.N. and Barron, K.M., 1998. Unusual upper mantle beneath Guaniamo, Guyana shield, Venezuela: Evidence from diamond inclusions. Geology, 26(11): 971-974.

Stachel, T., 2007. Diamond. Mineralogical Association of Canada Short Course Series, 37: 1-22.

Taylor, W.R., Jaques, A.L. and Ridd, M., 1990. Nitrogen-defect aggregation characteristics of some Australasian diamonds; timetemperature constraints on the source regions of pipe and alluvial diamonds. American Mineralogist, 75(11-12): 1290-1310.

Wyllie, P.J. and Huang, W.L., 1976. Carbonation and Melting Reactions in System Cao-MgO-SiO $2-\mathrm{CO}_{2}$ at Mantle Pressures with Geophysical and Petrological Applications. Contributions to Mineralogy and Petrology, 54(2): 79-107. 